\title{
Itinerário Terapêutico e Vulnerabilidade Social em Adultos com Doença Falciforme
}

\section{Rosana Brandão Vilela', Lorena Cardoso Caldas', Brunna Correia Santos ${ }^{1}$, Alexia Carneiro de Almeida ${ }^{1}$, Maria Alexsandra Silva ${ }^{1}$, Sidney José Santos ${ }^{2}$}

\author{
${ }^{1}$ Universidade Federal de Alagoas, Faculdade de Medicina, Maceió-Al, Brasil | \\ zanavilela@gmail.com; lorenancfcaldas@gmail.com; brunna_mac@hotmail.com; \\ alexiaalmeida@hotmail.com; maria_alexsandra_e@hotmail.com | https://orcid.org/0000- \\ 0003-3910-4678; https://orcid.org/0000-0002-2813-5498; https://orcid.org/0000-0003-1726- \\ 6019; https://orcid.org/0000-0003-2565-8696; https://orcid.org/0000-0002-3167-9357 \\ ${ }^{2}$ Associação das Pessoas com Hemoglobinopatias de Alagoas, Brasil | sid.s@globo.com | \\ https://orcid.org/0000-0003-0951-0413
}

Resumo: A reconstituição do itinerário terapêutico é uma tecnologia utilizada na prática da pesquisa qualitativa. Este estudo buscou analisar a vulnerabilidade social de pessoas adultas com doença falciforme (DF), por meio da reconstrução de itinerários terapêuticos. Trata-se de uma enfermidade hereditária, crônica, de alta prevalência no Brasil, que pode causar uma série de complicações ao longo da vida do indivíduo acometido. Na pesquisa foram entrevistados sete adultos (cinco mulheres e dois homens), com doença falciforme. Os participantes, selecionados de forma intencional, apresentaram em comum um histórico clínico e laboratorial de DF do tipo grave (SS). O material foi submetido à análise de conteúdo, na modalidade temática, utilizando as categorias indicadas previamente: (a) Renda, trabalho e escolaridade; (b) Interações familiar, social e amorosa; (c) Associação de pacientes e Internet. Os resultados da pesquisa demonstraram que a reconstituição de itinerários terapêuticos possibilita a compreensão dos variados modos da vulnerabilidade social na vida dessas pessoas, no estado de Alagoas, apresentando as diferenças e as similaridades nas formas de seu enfrentamento. Observou-se a vulnerabilidade social associada à precária comunicação sobre a doença, no ato da consulta médica, na escola e no trabalho. A inserção desses indivíduos em grupos de convivência, a exemplo das mídias sociais, trouxe benefícios como fonte de conhecimento, bem como canal de comunicação com outras pessoas com diagnóstico semelhante. Portanto, a reconstrução de itinerários terapêuticos mostrou-se uma importante ferramenta para: conhecer e avaliar esta dimensão analítica da vulnerabilidade e sua relação com o autocuidado em saúde; identificar a necessidade de ações mais efetivas visando oportunidades educacional, econômica, social e cultural; e favorecer a afirmação da experiência trazida pelas pessoas com doença falciforme.

Palavras-chave: Itinerário Terapêutico; Pesquisa Qualitativa; Doença Falciforme; Vulnerabilidade Social.

\section{Therapeutic Itinerary and Social Vulnerability in Adults with Sickle Cell Disease}

Abstract: The reconstruction of the therapeutic itinerary is a technology applied in the practice of qualitative research. This study intended to analyze the social vulnerability of adults with sickle cell disease, through the reconstruction of therapeutic itineraries. It is a hereditary, chronic disease, highly prevalent in Brazil, which can cause a series of complications throughout the life of the affected individual. In the survey, seven adults (five women and two men) with sickle cell disease were interviewed. The participants, selected intentionally, had in common a clinical and laboratory history of severe sickle cell disease (SS). The collected data were submitted to content analysis, in the thematic modality, applying the categories previously indicated: (a) Income, work and education; (b) Family, social and loving interactions; (c) Patient's support groups. The results of the study show that the reconstruction of therapeutic itineraries make it possible to understand the various types of social vulnerability in the lives of these people, in the state of Alagoas, showing the differences and similarities in the ways of coping. The link between social vulnerability and receiving little information about the disease when having a medical appointment either/ both in school and work was also observed/ considered in this study. The inclusion of these individuals in social groups - socia media, particularly - brought benefits such as source of knowledge, as well as a channel of communication with other people with a similar diagnosis. Therefore, therapeutic itinerary is an important tool for being aware and evaluate this analytical dimension of vulnerability and its linking with self-care regarding to health; identify the need for more effective actions aimed at educational, economic, social and cultural opportunities, and favor the affirmation of the experience brought by people with sickle cell disease.

Keywords: Therapeutic Itinerary; Qualitative Research; Sickle Cell Disease; Social Vulnerability. 


\section{Introdução}

A doença falciforme (DF) é definida como um conjunto de patologias hematológicas crônicas, hereditárias, as quais têm em comum a presença da hemoglobina $S(\mathrm{HbS})$ nas hemácias e apresentam impacto significativo na vida das pessoas e suas famílias (Zago, 2001).

A HbS é originada de uma mutação genética que afeta uma das bases nitrogenadas do ácido desoxirribonucleico (DNA) (Naoum, 2011). Esta hemoglobina, em baixas condições de oxigênio, assume a forma de foice, possibilitando o fenômeno vaso-oclusivo e hemólise (Zago, 2001). A doença se configura como uma condição crônica que exige cuidados continuados e prolongados. Ainda é compreendida como incurável, embora já existam potenciais tratamentos, como é o caso do Transplante de Medula Óssea (TMO) para receptores compatíveis dentro ou fora da família (Pieroni et al., 2007).

Dados do Ministério da Saúde estimam o nascimento de 3.500 bebês com a patologia a cada ano, evidenciando a relevância epidemiológica da doença no país. E uma das alterações genéticas mais frequentes no Brasil que se distribui de forma heterogênea, apresentando maior prevalência onde a proporção da população negra é maior, cujas frequências do gene variam de $2 \%$ a $3 \%$ em todo o país, aumentando para $6 \%$ a $10 \%$ entre pretos e pardos (Brasil, 2015). Este dado indica não apenas uma questão de raça, mas também de classe para a doença, visto que, no Brasil, a população negra está na base da pirâmide social e apresenta os piores indicadores epidemiológicos, educacionais e econômicos (Brasil, 2006; Figueró \& Ribeiro, 2017).

Um conjunto de ações e propostas, tais como diagnóstico por meio da triagem neonatal, prevenção com vacinas e antibioticoterapia profilática, bem como introdução da hidroxiureia, advindas, em especial, da influência do movimento negro sobre o poder público, modificou a expectativa de vida das pessoas acometidas pela DF. Esse aumento na longevidade das pessoas com DF demanda cuidados continuamente, uma vez que são pessoas que, em face do adoecimento crônico, da incapacidade e do sofrimento, convivem com estado de vulnerabilidade constante (Al Nagshabandi \& Abdulmutalib, 2019; Cançado \& Jesus, 2007; Marques, Cavalcanti \& Ruzzi-Pereira, 2015; Ferreira et al., 2013; Ohara, et al., 2012).

Vulnerabilidade é termo aplicável a diferentes campos temáticos, remetendo ao sentido de fragilidade, não apenas condicionada à ausência ou precariedade no acesso à renda, mas atrelada também às fragilidades de vínculos afetivo-relacionais e desigualdade de acesso a bens e serviços públicos. Na área da saúde, o conceito de vulnerabilidade tem presença na: Bioética, Saúde Mental, Saúde Ambiental, Epidemiologia (Carmo \& Guizardi, 2018).

Para Ayres et al. (2003) e Ayres (2009), a vulnerabilidade aparece, então, como uma possibilidade de buscar novas sínteses teóricas, de fazer a Epidemiologia dialogar com outras ciências e com outros saberes não científicos, uma possibilidade de construir saberes compreensivo-interpretativos, produtores de sínteses aplicadas. Trata-se da possibilidade de adoecimento do indivíduo de acordo com a sua situação, que pode estar relacionado as próprias características do indivíduo (vulnerabilidade individual), ao nível de coesão social construído durante a sua vida (vulnerabilidade social) ou ao grau de comprometimento governamental (âmbito programático).

Cronin et al. (2019) indicaram que fatores sociais impactavam no número de hospitalizações, no cuidado à saúde de pessoas com DF. A revisão integrativa realizada por Albrecht et al. (2016), que visou identificar as dimensões da vulnerabilidade, presentes na produção indexada na Biblioteca Virtual da Saúde, não encontrou estudos que abordassem diretamente a questão da vulnerabilidade individual e/ou social relacionadas a esta doença. 
Para compreender a vulnerabilidade social das pessoas adultas com DF, a presente pesquisa amparou-se na compreensão dos itinerários terapêuticos (IT), definidos como os diversos recursos acessados e os variados caminhos a serem percorridos pelos sujeitos na busca pelo cuidado em saúde. Vilela et al. (2019) constataram que a reconstituição do IT foi fundamental para visualizar as dificuldades vivenciadas pelas pessoas com DF na busca por cuidados em saúde, revelando assim a situação de vulnerabilidade programática vivenciada por esta população.

O IT compreende muito mais que a descrição linear das escolhas feitas pelo sujeito sobre os equipamentos institucionalizados de saúde, pois relaciona-se com uma variedade de saberes que se encontra próxima à sua realidade sociocultural, que lhe permite constituir compreensões e valores para lidar com seu processo de saúde-doença-cuidado.

Diante destes argumentos e da necessidade de maiores contribuições para o tema, justificou-se 0 desenvolvimento deste estudo pautado na seguinte pergunta: $A$ reconstrução dos itinerários terapêuticos (IT) possibilita compreender a vulnerabilidade social de pessoas adultas com DF? Desse modo, a presente investigação teve como objetivo analisar a vulnerabilidade social de pessoas adultas com DF, por meio da reconstrução de itinerários terapêuticos.

\section{Metodologia}

Trata-se de pesquisa descritiva, transversal e de abordagem quantitativa, derivada de uma pesquisa mais ampla, desenvolvida no período de 2017 a 2020, que teve como objetivo norteador: analisar a integralidade do cuidado a indivíduos com DF atendidos no estado de Alagoas, sob a perspectiva do trabalho em rede na atenção à saúde.

A pesquisa qualitativa permite trabalhar com o universo dos significados, fenômenos e processos que não podem ser quantificados, possibilitando a explicação do contexto social no qual o indivíduo está inserido, permitindo inferir sobre os acontecimentos produzidos em certa realidade (Minayo, 2015).

Para a pesquisa, foram entrevistadas sete pessoas adultas, sendo duas do sexo masculino, com idades de 30 e 32 anos, e cinco do sexo feminino, com idades variando de 20 a 40 anos. Os entrevistados apresentaram em comum um histórico clínico e laboratorial de DF do tipo grave (SS - anemia falciforme). A escolha dos participantes foi intencional procurando a representatividade e considerando que a extensão do objeto e a complexidade do estudo devem orientar o tamanho da amostra na pesquisa qualitativa (Minayo, 2015; Taquette \& Borges, 2020).

A produção do material empírico procedeu-se pela realização de entrevistas abertas, com foco nos caminhos utilizados para lidar com os agravos em saúde e/ou doenças, ou seja, os itinerários terapêuticos (IT).

IT é um termo que designa um conjunto de planos, estratégias e projetos voltados para um objeto preconcebido: o tratamento da aflição (Alves \& Souza,1999). Nesse sentido, estudos ressaltam a potência de sua análise na busca da influência exercida pelo contexto sociocultural durante o percurso de busca e realização do cuidado. A utilização da visão dos usuários pode ajudar na construção de políticas mais efetivas (Bellato et al., 2016).

Para tanto, partiu-se da seguinte solicitação: Conte-me a história de sua vida considerando a doença falciforme, desde a história que lhe contaram de quando você era criança, até os dias de hoje.

Todas as entrevistas foram efetuadas nos Centros de Referência (CRs) onde o sujeito realizava seu acompanhamento, por escolha do próprio participante, num único encontro, com a presença de, pelo menos, dois membros da equipe de pesquisa.

As narrativas foram gravadas em meio digital, com a anuência do entrevistado. Assim, cada entrevista caracterizou um texto, e o conjunto desses textos constituiu o corpus de análise desta pesquisa, representando a voz das pessoas com DF. 
O corpus da pesquisa que originou este artigo, entre outros, foi composto por 80 páginas digitadas em arquivo Word, fonte Times New Roman, tamanho 12, espaço simples, correspondendo à coleta realizada no período de julho de 2017 a fevereiro de 2019 .

Na última etapa do método foi realizada a análise de conteúdo, na modalidade temática, a qual, segundo Minayo (2015), tem como eixo central o "tema" que, por sua vez, comporta feixes de relações que podem ser apresentadas graficamente por uma palavra, frase ou resumo.

Neste estudo, a análise abordou dados das narrativas referentes a: situação socioeconômica, oportunidades de escolaridade e emprego, convívio social, e o papel da família e da associação de pacientes no enfrentamento das problemáticas advindas com a doença. Nesta etapa, tomou-se como base a noção de vulnerabilidade discutida por Ayres et al. (2003) e Ayres (2009), em que a vulnerabilidade social diz respeito ao modo como o indivíduo convive em um meio social no qual as pessoas experimentam possibilidades de participação social e política, acesso à educação, à saúde, à justiça, ao trabalho, aos benefícios sociais, à cultura, ao lazer e demais bens sociais (Ayres et al., 2003).

A pesquisa foi submetida ao Comitê de Ética, por meio da plataforma Brasil, e foi aprovada sob CAAE sob no 60437416.2.0000.5013. Com o intuito de preservar o anonimato dos participantes, os seus nomes foram substituídos por nomes de línguas faladas pelos negros de origem bantu.

\section{Resultados e Discussão}

Considerando a dimensão social, uma das perspectivas da vulnerabilidade, na busca por compreender como indivíduos e grupos de indivíduos se expõem a dado agravo à saúde (Ayres, 2009), três categoriais foram identificadas e constituídas previamente, são elas: Renda, trabalho e escolaridade; Interações familiar, social e amorosa; Grupos de apoio ao paciente.

\subsection{Renda, Trabalho e Escolaridade}

A variabilidade clínica da doença, que provoca diferença na gravidade e no sofrimento experimentados, contribuiu para percepções distintas em relação à repercussão da patologia nos processos que envolvem a renda, o trabalho e a escola.

Os participantes da pesquisa apresentavam renda individual e familiar baixa, variando de um a três salários mínimos. Quase a totalidade das pessoas com DF recebia benefício social, o que os auxiliava na manutenção das despesas domiciliares e na aquisição de medicamentos, entre outras necessidades:

A gente recebe um benefício através de mim, né? A minha mãe não trabalha, porque ela deixou de trabalhar porque eu adoecia muito quando pequena, então a gente vive do benefício (Ajaua).

Quem mantém uma casa, com o benefício que se tem, então às vezes pra manter a casa, pra manter a alimentação, pra manter alguma uma outra coisa, muitas vezes realmente não tem condições de comprar essa medicação (Tonga).

As condições sociais e econômicas das pessoas e familiares envolvidos na pesquisa demonstram que a presença da bolsa de prestação continuada (BPC), no valor de um salário mínimo, se torna essencial para a renda familiar. Essa insegurança financeira tem sido indicada como situação recorrente entre pessoas com doença falciforme e suas famílias e impacta diretamente a saúde (Cronin et al., 2019; Ohara et al., 2012). 
A exclusão do mercado de trabalho de pessoas com DF aparece em estreita relação com a baixa escolaridade, e também com a incapacidade de atender aos requisitos do empregador, em razão das crises álgicas recorrentes (Ferreira et al., 2013; Figueiró \& Ribeiro, 2017). Esta dificuldade foi observada em todas as narrativas dos participantes, independentemente do nível de escolaridade:

Aí, [a gente] vai para a entrevista e diz: tenho anemia falciforme, então pronto, acaba a entrevista ali. Isso é complicado pra gente, não tem oportunidade de emprego. O pessoal não quer dar oportunidade, que é assim trabalha uma semana, aí na outra semana já não vai, vai faltar, acho que eles pensam assim (Kioko).

As consequências das interrupções do ciclo escolar durante a infância e adolescência, ocasionadas pelas complicações da DF, e também o despreparo das instituições para lidar com esta condição foram enfatizadas nas narrativas:

Eu fazia o EJA, e o EJA é seis meses uma série e seis meses outra série. $E$ eu comecei a estudar em janeiro, aí quando foi em março, eu adoeci. Aí eu precisei ficar internada. Eu passei oito dias internada, tive alta. Eu acho que com quatro dias que eu tive alta, eu tive outra crise e precisei ficar internada de novo. Aí eu passei mais sete dias, depois tive alta, mas eu não fiquei indo pra escola, porque eu tive alta num dia e no outro dia, a dor voltou. Não forte, mas... leve, mas não tinha como eu ir pra escola. Aí eu lembro que eu perdi um mês de aula. Então eu só tinha atestado de um tempo, né? Dos tempo que eu fiquei internada. Eu ainda levei pra escola, falei com os professores, eu mostrei a eles. Eles disseram que iam colocar presença, mas no final de tudo eu tava cheia de falta e com certeza ia ficar reprovada. Aí eu desisti de estudar (Ajaua).

Neste estudo, assim como na literatura pesquisada, os pacientes parecem estar estudando mais. Porém, este fato não está associado a melhoria do nível socioeconômico deste grupo (Felix et al.., 2010; Amaral et al, 2015). Aqui, infere-se que a escolaridade teve reflexo direto na inserção das pessoas com DF no mercado de trabalho, e incentivou a dependência do auxílio financeiro oferecido pelo governo. Destaca-se que, em contexto de alta vulnerabilidade social, fatores como a baixa escolaridade podem implicar condições não apenas de emprego e renda, mas também de estilo de vida e saúde das pessoas com DF. Neste sentido, Al Nagshabandi e Abdulmutalib (2019) identificaram forte relação entre a gestão do autocuidado com o nível de educação, a condição de vida e a idade.

\subsection{Interações Familiar, Social e Amorosa}

O cuidado familiar foi representado em diversos aspectos, revelando que os participantes do estudo percebem a relevância do cuidado para a recuperação e estabilidade da saúde.

As narrativas mostram circunstâncias diferenciadas e repletas de cuidado:

[...] minha irmã já sabia cuidar de mim, que ela ficava com a minha mãe, quando eu tava internada. Aí a minha irmã explicava muito, também, o que era que tava acontecendo, o que é que podia acontecer e aí eu não tive medo nem hesitei. Eu sabia que ali eu tinha cuidado (Tonga).

Na verdade, toda a família sempre cuidou muito. Então sempre foram muito prestativos, porque não só eu, meu irmão tem a doença. Então todo mundo sempre apoiou muito. Quando eu precisava, todo mundo ia lá em casa pra ajudar. E minha mãe tinha que ir comigo pra o médico, aí meu pai ficava em casa cuidando da casa e ajudando a cuidar dos outros (Ronga).

O grupo entrevistado percebe a relevância do cuidado familiar para a recuperação e estabilidade da saúde. Para esses atores sociais, esse cuidado proporciona bem-estar. 
A busca pelo convívio social também foi percebida pelos participantes como um ponto relevante para a qualidade de vida, logo, a solidão se traduz como negativa para o bemestar. Porém, a fragilidade de saúde e as incapacidades impostas pela doença, associadas ao desconhecimento e preconceito da sociedade, tendem a enfraquecer a interação social e amorosa desses atores, com riscos de isolamento, como demonstra o relato de Ganguela:

Às vezes eu quero cavar um buraco, porque eu me acho estranha, porque $o$ povo fica olhando assim. Agora não, mas antes era com muita frequência. Muita, muita [...] eu lembro que a mãe dizia que algumas pessoas da família tinha medo da doença, da anemia falciforme, 'pra' não pegar nos filhos da pessoa [...] Eu até perguntei por uma, duas vezes, se era contagioso a anemia, pra minha mãe, porque eu percebi, eu criança, eu percebi, eu percebi (Ganguela).

Embora todos os participantes tivessem narrado experiências amorosas anteriores, no momento da pesquisa, apenas um vivenciava relacionamento. Os relatos mostram dificuldade em manter esse vínculo, seja por preconceito, seja por motivos adversos.

Agora eu não tenho não [namoro], mas já tive, tive quatro. Dois foi complicado, um foi mais ou menos e o outro foi por causa da anemia. As outras duas, veio descobrir quando eu fiquei doente aí contaram, aí nem quis saber. Nem perguntou nada, nem quis saber, tchau. E a outra foi também a família. Ela aceitou, mas a família acabou fazendo um inferno, dizia: - Você vai passar um dia em casa e um ano todinho no hospital (Kioko).

Por um grande tempo, período, eu evitei. Eu disse: - Não, ninguém vai aguentar namorar comigo, porque eu vivo sentindo dor. E tipo, eu posso cancelar um programa a qualquer momento. Mas depois disso, eu conheci um cara que ele disse que cuidava de mim, se ele pudesse, que queria ficar rico pra comprar medicação pra mim... Mas eu não quero medicação, eu já tenho muita. Aí depois disso eu parei mais de paranoia (Ronga).

Vários problemas, como: dificuldade no relacionamento familiar, na interação com colegas, no rendimento acadêmico e no desenvolvimento de uma autoimagem positiva, foram relacionados em estudos sobre DF (Costa et al., 2018; Marques, Cavalcanti \& RuzziPereira, 2015). Nesta investigação, a família é representada pelos participantes como um espaço de proteção e cuidado. A interação social mostrou-se prejudicada, especialmente pelo desconhecimento da doença pela sociedade e insegurança da pessoa com DF. Da mesma forma, referiram dificuldades de relacionamento afetivo e laços duradouros necessários para a formação da família que almejavam.

\subsection{Grupos de Apoio ao Paciente}

Os movimentos associativos de pacientes são redes formadas geralmente por pacientes, familiares e/ou profissionais de saúde que investem na remediação das faltas do sistema de saúde oficial, no compartilhamento de experiências, fortalecimento de vínculos e afetividade entre os pares (Barbosa, 2015; Silva et al., 2013). As associações de pacientes com DF, além dos atributos supracitados, elas possuem um importante papel na construção de autoestima e protagonismo diante o adoecimento (Andrade \& Vaitsman, 2002).

As narrativas deste estudo confirmam a importância da Associação, porém, verificou-se pouca frequência às atividades presenciais, ocasionada por: dificuldades na locomoção, metodologias de abordagem da temática, entre outros fatores:

Quando a gente participava da Associação, o X entregava alguns panfletos que tem explicando detalhadamente os sintomas, várias coisas, e a gente foi aprendendo pelos panfletos e foi aprendendo com a doença mesmo (Ajaua). 
A Associação precisa do sim de cada um, primeiramente o meu. Não é somente chegar, sentar numa cadeira e ouvir aquilo que uma pessoa tem, mas eu também preciso buscar pra poder interagir com a Associação. (Bemba).

O uso da Internet e das mídias sociais representam um papel de destaque como fonte de conhecimento dos entrevistados, bem como canal de comunicação com outras pessoas com diagnóstico semelhante. A facilidade no acesso, linguagem simples e prática, apresenta um atrativo como ferramenta de democratização da informação.

\section{[...] [conhecia a doença] nos livretos que a gente ganhava sobre anemia falciforme e também na internet. Então... até com a dra Y mesmo, eu ia juntando as peças até começar a entender mais. Só que quando eu entrei na internet, aí pronto! Já era! Foi que eu encontrei bem mais [...] O médico fala muito complicado. É só falar, tipo, o básico. Aí anota no caderninho tudo pra pesquisar quando chegar em casa (Ronga).}

O uso das mídias permite que pessoas com DF e/ou seus familiares externem experiências de adoecimentos, de sofrimentos e de solidariedades (Gomberb et al., 2017). Esta investigação mostrou que a internet rompeu fronteiras geográficas, ajudou no investimento do autocuidado e surge como uma potente ferramenta para o fortalecimento da Associação de pacientes.

Existe uma associação estatisticamente positiva entre a capacidade de controle da doença (autoeficácia) e o gerenciamento do autocuidado em pessoas com DF (AI Nagshabandi \& Abdulmutalib, 2019). A alta vulnerabilidade social associada à precária comunicação no ato da consulta médica, na escola e no trabalho, evidenciadas neste estudo, ressaltaram a necessidade de empreender esforços de novas pesquisas e planejamento de intervenções para alcançar melhores resultados de saúde em pessoas adultas com DF no estado de Alagoas.

\section{Conclusões}

O estudo sobre os itinerários terapêuticos possibilitou compreender os variados modos da vulnerabilidade social na vida de pessoas com DF do estado de Alagoas, apresentando as diferenças e as similaridades nas formas de seu enfrentamento.

Os resultados da análise deste estudo denotaram complexidade na produção da vulnerabilidade social das pessoas adultas com DF residentes no estado de Alagoas. Identificaram, ainda, que aspectos referentes à educação, à renda, às oportunidades de trabalho, à falta de investimento na informação sobre a doença, à fragilidade na formação dos professores e profissionais de saúde, e dificuldades relativas à associação de pacientes podem, num contexto desfavorável, gerar um precário cuidado para estas pessoas.

Tais resultados também delinearam que a inserção desses indivíduos em grupos de convivência, a exemplo das mídias sociais, traz benefícios para a interação, bem como favorece mudanças no estilo de vida e na manutenção de bem-estar.

Embora as pesquisas que buscam compreender as conexões entre a vulnerabilidade social e o cuidado em saúde no país sejam recentes e careçam de acúmulo que apoie afirmações mais robustas, elas podem gerar reflexões sobre o tipo de estratégias com potencial para diminuir a vulnerabilidade social das pessoas adultas com DF. Neste sentido, reitera-se a importância do diálogo qualificado com os sujeitos implicados, na busca de ouvir suas necessidades, seus anseios e suas críticas.

Portanto, o levantamento e a identificação dos IT das pessoas com DF - a experiência com a doença ao ser narrada - possibilitaram a ampliação do conhecimento sobre a DF e vulnerabilidade social, bem como provocou a afirmação das pessoas com a doença. 


\section{Agradecimentos}

Esta investigação foi financiada pelo DAGEP/SGEP - Ministério da Saúde, FAMED/UFAL, e PIBIC/CNPq.

\section{Referências}

Al Nagshabandi, E. A., \& Abdulmutalib, I. A. M. (2019). Self-care management and self-efficacy among adult patients with sickle cell disease. American Journal of Nursing Research, 7(1), 51-57.

Albrecht, C. A. M., Aarts, K. M., Brum, M. L. B., Rosa, R.S., \& Bordin, R. (2016). Anemia falciforme e dimensões da vulnerabilidade: uma revisão da produção indexada na Biblioteca Virtual da Saúde. In Comunicação apresentada no V Congresso Online- Gestão, Educação e Promoção da Saúde. São Paulo, SP, Brasil. https://artigosconvibra.s3.amazonaws.com/2016_72_12736.pdf

Alves, P. C. B., \& Souza, I. M. A. (1999). Escolha e avaliação de tratamento para problemas de saúde: considerações sobre itinerário terapêutico. In M. C. M. Rabelo (Org.), Experiência de doenças e narrativas (pp. 125-137). Rio de Janeiro: Fiocruz.

Amaral, J. L., Almeida, N. A., Santos, P. S., de Oliveira, P. P., \& Lanza, F. M. (2015). Perfil sociodemográfico, econômico e de saúde de adultos com doença falciforme. Rev Rene, 16(3), 296-305.

Andrade, G. R., \& Vaitsman, J. (2002). Apoio social e redes: conectando solidariedade e saúde. Ciência \& Saúde Coletiva, 7, 925-934.

Ayres, J. R. C. M., França Júnior, I., Calazans, G. J., \& Saletti Filho, H. C. (2003). O conceito de vulnerabilidade e as práticas de saúde: novas perspectivas e desafios. Promoção da Saúde: Conceitos, Reflexões, Tendências, 2, 121-144.

Ayres, J. R. D. C. M. (2009). Organização das ações de atenção à saúde: modelos e práticas. Saúde e Sociedade, 18, 11-23.

Barbosa, R. L. (2015). Associações de Pacientes, Associações de Doentes, Organizações de Pacientes, Grupos Consumidores de Saúde... afinal, sobre o que se está falando?. Cescontexto-Debates, (9), 20-33.

Bellato, R., Araújo, L. F. de, Maruyama, S. A. T., \& Ribeiro, A. L. (2016). História de vida como abordagemprivilegiada para compor itinerários terapêuticos. In T. E. Gerhardt, R. Pinheiro, E. N. F. Ruiz, \& A. G. da Silva Junior (Orgs.), Itinerários Terapêuticos: integralidade no cuidado, avaliação e formação em saúde (pp. 203-221). Rio de Janeiro: CEPESC/IMS/UERJ. Retrieved from https://cepesc.org.br/wp-content/uploads/2017/07/livro-itinerariosterapeuticos-1.pdf.

Brasil. Ministério da Saúde. (2015). Doença falciforme: conhecer para cuidar. Brasília, DF: Ministério da Saúde.

Brasil. Ministério da Saúde. (2006). Saúde Brasil 2006: Uma análise da situação de saúde no Brasil. Brasília, DF: Ministério da Saúde.

Cançado, R. D., \& Jesus, J. A. (2007). A doença falciforme no Brasil Sickle cell disease in Brazil. Revista Brasileira de Hematologia e Hemoterapia, 29(3), 204-206.

Carmo, M. E. D., \& Guizardi, F. L. (2018). O conceito de vulnerabilidade e seus sentidos para as políticas públicas de saúde e assistência social. Cadernos de Saúde Pública, 34, e00101417.

Costa, D. O., Araújo, F. A., Xavier, A. S. G., Araújo, L. D. S., Silva, U. B. D., Santos, E. A., \& Ferreira, S. L. (2018). Autocuidado de homens com priapismo e doença falciforme. Revista Brasileira de Enfermagem, 71(5), 2418-2424.

Cronin, R. M., Hankins, J. S., Byrd, J., Pernell, B. M., Kassim, A., Adams-Graves, P., Thompson, A., Kalinyak, K., DeBaun, M., \& Treadwell, M. (2019). Risk factors for hospitalizations and readmissions among individuals with sickle cell disease: results of a US survey study. Hematology, 24(1), 189-198. 
Felix, A. A., Souza, H. M., \& Ribeiro, S. B. F. (2010). Aspectos epidemiológicos e sociais da doença falciforme. Revista Brasileira de Hematologia e Hemoterapia, 32(3), 203-208.

Ferreira, S. L., Cordeiro, R. C., dos Santos, F. C., \& Silva, L. S. da. (2013). Vulnerabilidade de pessoas adultas com doença falciforme: subsídios para o cuidado de enfermagem. Ciência, Cuidado e Saúde, 12(4), 711-718.

Figueiró, A. V. M., \& Ribeiro, R. L. R. (2017). Vivência do preconceito racial e de classe na doença falciforme. Saúde e Sociedade, 26, 88-99.

Gomberg, E., Mandarino, A. C. de S., Mandarino Junior, H. de C., \& Borges, W. C. (2017). Visibilidades virtuais de uma Associação de Pessoas com Doença Falciforme na Bahia, Brasil: enfrentamentos e empoderamentos pelo Facebook. Forum Sociológico, 30.

Marques, L. N., Cavalcanti, A., \& Ruzzi-Pereira, A. (2015). O viver com a doença falciforme: percepção de adolescentes. Revista de Terapia Ocupacional da Universidade de São Paulo, 26(1), 109-117.

Minayo, M. C. S. (2015). O desafio do conhecimento: pesquisa qualitativa em saúde. São Paulo: Hucitec.

Naoum, P. C. (2011). Sickle cell disease: from the beginning until it was recognized as a public health disease. Revista Brasileira de Hematologia e Hemoterapia 33(1), 1-10.

Ohara, D. G., Ruas, G., Castro, S. S., Martins, P. R., \& Walsh, I. A. (2012). Dor osteomuscular, perfil e qualidade de vida de indivíduos com doença falciforme. Revista Brasileira de Fisioterapia, 16(5), 431-438.

Pieroni, F., Barros, G. M. N., Voltarelli, J. C., \& Simões, B. P. (2007). Transplante de células-tronco hematopoiéticas (TCTH) em doenças falciformes. Revista Brasileira de Hematologia e Hemoterapia, 29(3), 327-330.

Santos, B. C. O., Caldas, L. N. C. F., Almeida, A. C., Vilela, R. Q. B., Riscado, J. L. S., Santos, S., \& Cunha, M. F. S. (2018). Triagem neonatal para hemoglobinopatias no estado de Alagoas. In Poster apresentado no Congresso Brasileiro de Hematologia e Hemoterapia HEMO2018. São Paulo, SP, Brasil.

Silva, A. H., Bellato, R., \& Araújo, L. (2013). Cotidiano da família que experiência a condição crônica por anemia falciforme. Revista Eletrônica de Enfermagem, 15(2), 437-446.

Taquette, S.R., \& Borges, L. (2020). Pesquisa qualitativa para todos. Petrópolis: Vozes.

Vilela, R., Caldas, L., Correia, B., Almeida, A., Silva, M. A., \& Santos, S. J. (2019). A integralidade do cuidado em saúde na doença falciforme: uso de itinerário terapêutico no apoio à pesquisa qualitativa avaliativa. CIAIQ2019, 2, 746-755.

Zago, M. A. (2001). Anemia falciforme e doenças falciformes. In E. Hamann, \& P. Tauil (Orgs.), Manual de doenças mais importantes, por razões étnicas, na população afro-descendente (pp. 13-35). Brasília: Secretaria de Políticas da Saúde, Ministério da Saúde. 